\title{
Health-Related Predictors of Quality of Life in Cancer Patients in Saudi Arabia
}

\author{
Anwar E. Ahmed ${ }^{1,2}$ • Alaa S. Almuzaini ${ }^{2}$ - Mohannad A. Alsadhan ${ }^{3}$. \\ Abdulrahman G. Alharbi ${ }^{4}$ - Hanin S. Almuzaini ${ }^{2}$ - Yosra Z. Ali ${ }^{5}$. \\ Abdul-Rahman Jazieh ${ }^{5}$
}

Published online: 7 March 2017

(C) The Author(s) 2017. This article is published with open access at Springerlink.com

\begin{abstract}
Research on Saudi Arabian cancer patients is a priority at King Abdulaziz Medical City (KAMC), Riyadh, Saudi Arabia. Because there is limited research on the quality of life (QoL) of Saudi Arabian cancer patients, the aim of this study was to identify the predictors of the QoL in a sample of Saudis with cancer. In August 2016, a cross-sectional study was conducted on 438 patients with a variety of cancer types
\end{abstract}

Anwar E. Ahmed

ahmedan@ngha.med.sa; ahmeda5@vcu.edu

Alaa S. Almuzaini

Almuzaini.a.s@gmail.com

Mohannad A. Alsadhan

mohannadalsadhan@gmail.com

Abdulrahman G. Alharbi

Dr.harbi93@gmail.com

Hanin S. Almuzaini

Almuzaini.h.s@gmail.com

Yosra Z. Ali

aliyz@vcu.edu

Abdul-Rahman Jazieh

jazieha@ngha.med.sa

1 King Abdullah International Medical Research Center (KAIMRC), Riyadh, Saudi Arabia

2 King Saud bin Abdulaziz University for Health Sciences, Riyadh, Saudi Arabia

3 College of Medicine, King Saud University, Riyadh, Saudi Arabia

4 College of Medicine, Imam Abdulrahman Al Faisal University, Dammam, Saudi Arabia

5 Department of Oncology, King Abdulaziz Medical City, Riyadh, Saudi Arabia
(145 breast, 109 colorectal, 38 leukemia, 45 lymphoma, and 99 other types) who attended the Oncology Outpatient Clinics at KAMC. Sociodemographics, clinical symptoms, and cancer treatments were collected for each patient. We used the SF36 instrument to assess QoL. Of the cancer patients studied, $28.4 \%$ had a family history of cancer, and, according to subgroup analyses, the elderly, those lacking formal education, the unemployed, those diagnosed with Stage III/IV, and those with metastasis had significantly worse physical functions than the other cancer patients. According to multiple linear regression analyses, cancer patients who exercised regularly tended to have better physical function, emotional role function, vitality, social function, and general health (increase in SF-36 scores of $8.82,9.75,5.54,6.66$, and 4.97 , respectively). Patients with first-year-after-cancer diagnosis tended to have poor emotional wellbeing, social function, and general health (decrease in SF-36 scores of 5.20, 7.34, and 6.12, respectively). Newly diagnosed cancer patients and patients who did not exercise tended to experience significantly poor QoL in several domains; thus, the effectiveness of exercise must be assessed in Saudi cancer patients as an intervention to improve QoL.

Keywords SF-36 $\cdot$ QoL $\cdot$ Regular exercise $\cdot$ First-year-cancer diagnosis $\cdot$ Saudi Arabia

\section{Introduction}

According to the Saudi Ministry of Health Cancer Registry in Riyadh, more than 15,653 people in Saudi Arabia (77.6\% were Saudis) were diagnosed with cancer in 2013. The crude incidence rate was 57.5 per 100,000 population per year. The Saudi Government's vision for 2030 is to significantly mitigate the challenges faced by the health sector in preventing cancers through analyzing independent risk factors and 
improving health and control cancer outcomes through treating the symptoms of cancers.

Cancer not only affects patients physically, but it may also impact the quality of life (QoL) of cancer survivors negatively $[1,2]$. Recently, much attention has been paid to the negative impact of cancer and its treatment on the QoL in cancer patients. Several reports have indicated that greater QoL impairment in patients with cancer may be attributable to treatment side effects, cancer symptoms, and psychological distress [2-4].

There is evidence that older age has negative effects on the QoL in cancer patients $[5,6]$, while gender has an influence on the degree of QoL impairment [7]. Lack of education has a negative effect on cancer patients [7], and low income has also been negatively associated with QoL in cancer patients [8-11]. Other factors contributing to QoL impairment may include clinical presentations of cancer patients such as the stage, type, and site of the cancer [7, 12]. It has been documented internationally that measuring the quality of life in cancer patients is an important aspect of cancer management and treatment, and could serve as an effective tool for clinical trials $[1,13-15]$.

To date, research on QoL in cancer patients in Saudi Arabia has been insufficient. Only three studies in Saudi Arabia have addressed the quality of life in cancer patients. Colorectal cancer [16] and breast cancer [17, 18] patients were reported to have a low QoL. According to the authors, there are numerous factors associated with a major reduction in all domains of QoL, including educational level, employment status, pathological staging, and tumor location [16-18]. There are numerous self-report questionnaires used to measure QoL, including the European Organization for Research and Treatment of Cancer (EORTC) quality of life [19] which is used by Almutairi et al. The Short-Form Health Survey SF-36 (the RAND 36-item) questionnaire [20] is a self-report questionnaire commonly used to assess QoL, and it has been used consistently in Saudi patients with sickle cell disease [21, 22]. However, there is a paucity of data using SF-36 measure in Saudi cancer patients.

The impact of sociodemographics, cancer characteristics, and treatment are important to consider when assessing QoL in the cancer population. It allows clinicians to describe and assess the health status of cancer patients, provide interventions, and measure their effectiveness. This study is of interest to oncologists who provide routine care to cancer patients in Saudi Arabia. Research on Saudi Arabian cancer patients is a priority at King Abdulaziz Medical City (KAMC), Riyadh, Saudi Arabia. In this study, we used data from a study conducted at King Abdulaziz Medical City in Riyadh (KAMC-R) to determine the impact of sociodemographics, clinical symptoms, and cancer treatments on QoL measures in Saudi cancer patients. We hypothesized that being elderly, newly diagnosed patients, and the cancer prognosis would have a negative impact on QoL in Saudi cancer patients. We also hypothesized that exercise may impact QoL positively in cancer patients.

\section{Materials and Methods}

A survey study was conducted in the outpatient oncology clinics, KAMC, Ministry of National Guard Health Affairs. The study obtained scientific and ethical approval from the IRB office at King Abdullah International Medical Research Center (KAIMRC), Riyadh (\# RSS16/004). The study included a consecutive sample of cancer patients with different types of cancer who were attending outpatient oncology clinics for follow-up with oncology specialists during the study period (August 14-31/2016). The subjects of the study administered a one-time survey with a consent form explaining the aims of the study and asking whether they wanted to complete the survey. Assent was obtained from parents of all cancer patients with ages between 14 and 17 years. We obtained written consent from those patients age 18 years and above.

A total of 540 subjects who consented were administered the survey, and 436 surveys were completed and returned (145 breast, 45 lymphoma, 109 colorectal, 38 leukemia, and 99 other types of cancer) with a response rate of $80.7 \%$. Sociodemographics data were collected for each patient such as age, gender, height, weight, university degree, marital status, regular exercise, family support, and employment status. We collected clinical data on patients and their cancer characteristics such as type of cancer, family history of cancer, cancer stage (I, II, III, or IV), multiple tumors, newly diagnosed cancer patients or first-year-after-cancer diagnosis, whether patient received chemotherapy, whether patient had surgery to remove tumors, whether patient received immunotherapy, whether patient received radiation therapy antibiotics, side effects of treatment, metastasis, sleep deprivation, fever, and chronic disease other than cancer. The following section describes the quality of life questionnaire used to assess patients' health status.

\section{Quality of Life Instrument}

Quality of life was assessed by the Medical Outcomes Study 36-item short-form (SF-36) questionnaire [20], an instrument with an Arabic version [23] and established reliability that provides subjective evaluation of quality of life. It has been used in general and disease-specific populations. The SF-36 is a self-rated tool comprising 36 items grouped into eight domains: physical function, physical role health, emotional role functions, vitality, emotional wellbeing, social function, bodily pain, and general health. Each of these domains ranges from 0 (poor health) to 100 (best health). The SF-36 questionnaire was found to be reliable in this population with Cronbach's 
alpha values ranging between 0.60 "social function" and 0.91 "physical function."

\section{Data Analysis}

The data analysis was conducted using IBM SPSS Statistics 23 (SPSS, Chicago, IL). Patients' characteristics: sample statistics such as means and standard deviation were used to summarize numerical data. Counts and percentages were used to summarize categorical data (Table 1). Bivariate analyses: In order to account for 24 multiple comparisons, the Bonferroni correction of $\alpha / n=0.05 / 24=0.0021$ was used to compare QoL differences between sociodemographics and clinical characteristics (Tables 1 and 2, Fig. 1). Multivariate analyses: Multiple linear regression models were used to examine the relationship between the sociodemographics, clinical symptoms, and cancer treatments and each QoL domain, and to identify predictors of the SF-36 subscales. Regression coefficients were used to interpret the linear regression findings. In all multivariate analyses, the significance level $(\alpha)$ was set at 0.05 .

Table 1 Differences in quality of life by sociodemographics and clinical characteristics $(N=436)$

\begin{tabular}{|c|c|c|c|c|c|c|c|c|c|c|c|c|c|c|c|}
\hline \multirow[b]{2}{*}{ Characteristics } & & \multicolumn{2}{|c|}{ Overall } & \multicolumn{3}{|c|}{ Physical functioning } & \multicolumn{3}{|c|}{$\begin{array}{l}\text { Role limitations due } \\
\text { to physical health }\end{array}$} & \multicolumn{3}{|c|}{$\begin{array}{l}\text { Role limitations due to } \\
\text { emotional problems }\end{array}$} & \multicolumn{3}{|c|}{ Vitality } \\
\hline & & $n$ & $\%$ & Mean & $\mathrm{SD}$ & $P$ & Mean & SD & $P$ & Mean & $\mathrm{SD}$ & $P$ & Mean & $\mathrm{SD}$ & $P$ \\
\hline \multirow[t]{2}{*}{ Gender } & Male & 157 & 36.0 & 46.8 & 30.8 & 0.429 & 24.7 & 36.6 & 0.620 & 33.3 & 41.9 & 0.507 & 44.0 & 21.6 & 0.924 \\
\hline & Female & 279 & 64.0 & 49.1 & 28.7 & & 26.5 & 37.6 & & 30.6 & 41.2 & & 43.8 & 22.3 & \\
\hline \multirow[t]{2}{*}{ Elderly } & No & 270 & 61.9 & 55.1 & 27.6 & $0.001 *$ & 25.8 & 37.3 & 0.985 & 32.1 & 41.0 & 0.737 & 46.1 & 22.0 & 0.009 \\
\hline & Yes & 166 & 38.1 & 37.2 & 29.0 & & 25.9 & 37.1 & & 30.7 & 42.2 & & 40.4 & 21.7 & \\
\hline \multirow[t]{2}{*}{ University } & No & 312 & 71.6 & 44.1 & 28.8 & $0.001 *$ & 25.9 & 37.0 & 0.985 & 29.9 & 40.6 & 0.185 & 42.2 & 22.1 & 0.010 \\
\hline & Yes & 124 & 28.4 & 58.9 & 28.4 & & 25.8 & 37.8 & & 35.8 & 43.4 & & 48.2 & 21.2 & \\
\hline \multirow[t]{2}{*}{ Employed } & No & 321 & 73.6 & 45.6 & 28.3 & $0.001 *$ & 26.5 & 37.0 & 0.562 & 31.5 & 41.5 & 0.926 & 43.2 & 21.8 & 0.246 \\
\hline & Yes & 115 & 26.4 & 56.0 & 31.2 & & 24.1 & 37.7 & & 31.9 & 41.5 & & 46.0 & 22.4 & \\
\hline \multirow[t]{2}{*}{ Married } & No & 99 & 22.7 & 47.2 & 30.1 & 0.678 & 30.3 & 38.8 & 0.177 & 32.0 & 40.1 & 0.911 & 45.2 & 23.6 & 0.524 \\
\hline & Yes & 337 & 77.3 & 48.6 & 29.3 & & 24.6 & 36.6 & & 31.5 & 41.9 & & 43.5 & 21.5 & \\
\hline \multirow[t]{2}{*}{ Obese } & No & 273 & 71.7 & 50.1 & 29.2 & 0.217 & 28.0 & 38.9 & 0.216 & 32.8 & 42.3 & 0.460 & 44.4 & 21.6 & 0.876 \\
\hline & Yes & 108 & 28.3 & 45.9 & 31.3 & & 22.9 & 35.0 & & 29.3 & 40.9 & & 44.0 & 23.7 & \\
\hline \multirow[t]{2}{*}{ Family history of cancer } & No & 312 & 71.6 & 47.5 & 29.7 & 0.339 & 27.6 & 37.9 & 0.112 & 33.3 & 42.3 & 0.147 & 44.9 & 22.4 & 0.129 \\
\hline & Yes & 124 & 28.4 & 50.4 & 28.6 & & 21.4 & 35.0 & & 27.2 & 39.0 & & 41.4 & 20.7 & \\
\hline \multirow[t]{2}{*}{ 1st year after cancer diagnosis } & No & 196 & 45.1 & 46.9 & 28.1 & 0.405 & 21.8 & 33.7 & 0.045 & 32.0 & 41.5 & 0.800 & 42.5 & 23.3 & 0.243 \\
\hline & Yes & 239 & 54.9 & 49.2 & 30.4 & & 28.9 & 39.4 & & 31.0 & 41.3 & & 45.0 & 20.8 & \\
\hline \multirow[t]{5}{*}{ Cancer Types } & Breast & 145 & 33.3 & 54.4 & 28.8 & $0.002 *$ & 29.3 & 38.3 & 0.292 & 33.6 & 42.2 & 0.137 & 43.9 & 20.8 & 0.242 \\
\hline & Colorectal & 109 & 25.0 & 42.7 & 26.6 & & 23.4 & 35.1 & & 32.1 & 41.6 & & 41.2 & 22.4 & \\
\hline & Leukemia & 38 & 8.7 & 52.9 & 29.5 & & 23.7 & 37.2 & & 23.7 & 38.7 & & 42.1 & 23.4 & \\
\hline & Lymphoma & 45 & 10.3 & 52.8 & 29.7 & & 32.8 & 39.8 & & 43.0 & 42.4 & & 50.0 & 24.8 & \\
\hline & Others & 99 & 22.7 & 41.7 & 31.2 & & 21.2 & 36.3 & & 25.9 & 40.0 & & 44.8 & 21.2 & \\
\hline \multirow[t]{2}{*}{ Stage III/IV } & $\mathrm{I} / \mathrm{II}$ & 216 & 58.7 & 53.1 & 29.4 & $0.001 *$ & 29.2 & 38.3 & 0.006 & 36.0 & 43.2 & $0.001 *$ & 47.4 & 20.3 & $0.001 *$ \\
\hline & III/IV & 152 & 41.3 & 42.0 & 29.1 & & 18.9 & 32.9 & & 22.1 & 36.2 & & 38.6 & 22.5 & \\
\hline \multirow[t]{2}{*}{ Multiple tumors } & No & 291 & 68.5 & 49.9 & 29.6 & 0.034 & 28.7 & 38.5 & 0.003 & 35.9 & 42.8 & $0.001 *$ & 46.5 & 21.7 & $0.001 *$ \\
\hline & Yes & 134 & 31.5 & 43.4 & 28.9 & & 18.1 & 31.8 & & 22.6 & 36.9 & & 37.5 & 21.4 & \\
\hline \multirow[t]{2}{*}{ Cancer surgery } & No & 199 & 45.6 & 48.1 & 30.5 & 0.890 & 25.0 & 37.3 & 0.659 & 30.5 & 41.0 & 0.615 & 43.6 & 21.3 & 0.800 \\
\hline & Yes & 237 & 54.4 & 48.5 & 28.6 & & 26.6 & 37.2 & & 32.5 & 41.8 & & 44.2 & 22.6 & \\
\hline Chemotherapy & No & 101 & 23.2 & 48.2 & 29.8 & 0.958 & 33.7 & 41.3 & 0.027 & 38.3 & 45.1 & 0.082 & 46.6 & 22.5 & 0.164 \\
\hline & Yes & 335 & 76.8 & 48.3 & 29.4 & & 23.5 & 35.6 & & 29.6 & 40.1 & & 43.1 & 21.8 & \\
\hline Radiation therapy & No & 238 & 54.7 & 50.3 & 29.8 & 0.142 & 29.0 & 39.3 & 0.055 & 33.3 & 41.8 & 0.352 & 46.4 & 22.6 & 0.009 \\
\hline & Yes & 197 & 45.3 & 46.1 & 28.7 & & 22.2 & 34.2 & & 29.6 & 41.1 & & 40.9 & 20.9 & \\
\hline Immunotherapy & No & 206 & 47.5 & 51.3 & 30.7 & 0.054 & 28.5 & 40.3 & 0.149 & 37.1 & 44.3 & 0.010 & 47.0 & 21.2 & 0.007 \\
\hline & Yes & 228 & 52.5 & 45.9 & 27.9 & & 23.4 & 34.0 & & 26.8 & 38.2 & & 41.3 & 22.3 & \\
\hline Antibodies & No & 319 & 75.2 & 49.9 & 29.1 & 0.115 & 26.8 & 38.3 & 0.477 & 34.6 & 43.0 & 0.013 & 45.2 & 22.4 & 0.123 \\
\hline & Yes & 105 & 24.8 & 44.6 & 31.1 & & 23.8 & 34.4 & & 23.8 & 36.3 & & 41.3 & 20.8 & \\
\hline Metastasis & No & 303 & 69.5 & 51.2 & 29.0 & $0.002 *$ & 28.5 & 38.5 & 0.016 & 35.1 & 42.9 & 0.005 & 46.9 & 21.7 & $0.001 *$ \\
\hline & Yes & 133 & 30.5 & 41.8 & 29.5 & & 19.7 & 33.4 & & 23.6 & 36.9 & & 37.2 & 21.3 & \\
\hline Fever & No & 263 & 60.3 & 50.4 & 30.7 & 0.058 & 30.1 & 39.5 & $0.002 *$ & 38.1 & 43.9 & $0.001 *$ & 46.8 & 22.1 & $0.001 *$ \\
\hline & Yes & 173 & 39.7 & 45.1 & 27.1 & & 19.4 & 32.4 & & 21.6 & 35.2 & & 39.6 & 21.1 & \\
\hline Family support & No & 37 & 8.5 & 49.9 & 33.0 & 0.736 & 26.4 & 35.3 & 0.933 & 42.3 & 45.6 & 0.137 & 43.4 & 25.7 & 0.878 \\
\hline & Yes & 399 & 91.5 & 48.2 & 29.1 & & 25.8 & 37.4 & & 30.6 & 40.9 & & 44.0 & 21.7 & \\
\hline Chronic disease other than & No & 271 & 62.2 & 52.0 & 29.1 & $0.001^{*}$ & 25.9 & 38.4 & 0.964 & 29.4 & 40.7 & 0.160 & 44.7 & 21.7 & 0.358 \\
\hline cancer & Yes & 165 & 37.8 & 42.2 & 29.0 & & 25.8 & 35.3 & & 35.2 & 42.5 & & 42.7 & 22.5 & \\
\hline Regular exercise & No & 293 & 67.2 & 44.4 & 29.6 & $0.001 *$ & 23.2 & 36.1 & 0.038 & 28.0 & 41.0 & 0.009 & 41.1 & 21.6 & $0.001^{*}$ \\
\hline & Yes & 143 & 32.8 & 56.2 & 27.4 & & 31.3 & 39.0 & & 38.9 & 41.5 & & 49.7 & 21.7 & \\
\hline
\end{tabular}

*The variable is significant using Bonferroni correction cut-off at $\alpha / n=0.05 / 24=0.0021$, where $n$ is the number of tests, $P=\mathrm{P}$-value. 
Table 2 Differences in quality of life by sociodemographics and clinical characteristics $(N=436)$

\begin{tabular}{|c|c|c|c|c|c|c|c|c|c|c|c|c|c|}
\hline \multirow[b]{2}{*}{ Characteristics } & & \multicolumn{3}{|c|}{ Emotional wellbeing } & \multicolumn{3}{|c|}{ Social functioning } & \multicolumn{3}{|l|}{ Pain } & \multicolumn{3}{|c|}{ General health } \\
\hline & & Mean & SD & $P$ & Mean & $\mathrm{SD}$ & $P$ & Mean & SD & $P$ & Mean & SD & $P$ \\
\hline \multirow[t]{2}{*}{ Gender } & Male & 63.7 & 19.7 & 0.479 & 55.7 & 26.8 & 0.470 & 56.0 & 27.0 & 0.020 & 51.7 & 16.7 & 0.528 \\
\hline & Female & 62.3 & 20.4 & & 57.7 & 27.7 & & 49.7 & 26.8 & & 50.5 & 18.3 & \\
\hline \multirow[t]{2}{*}{ Elderly } & No & 62.1 & 20.9 & 0.374 & 58.9 & 27.2 & 0.065 & 51.4 & 27.7 & 0.557 & 52.2 & 18.0 & 0.054 \\
\hline & Yes & 63.9 & 18.9 & & 53.9 & 27.4 & & 52.9 & 25.9 & & 48.9 & 17.1 & \\
\hline \multirow[t]{2}{*}{ University } & No & 62.2 & 19.9 & 0.344 & 56.8 & 27.8 & 0.786 & 50.2 & 27.3 & 0.030 & 49.6 & 17.9 & 0.009 \\
\hline & Yes & 64.3 & 20.7 & & 57.6 & 26.2 & & 56.4 & 26.0 & & 54.4 & 17.0 & \\
\hline \multirow[t]{2}{*}{ Employed } & No & 62.8 & 19.6 & 0.978 & 57.7 & 26.6 & 0.389 & 51.5 & 26.1 & 0.584 & 49.9 & 17.5 & 0.054 \\
\hline & Yes & 62.9 & 21.7 & & 55.1 & 29.3 & & 53.2 & 29.6 & & 53.7 & 18.2 & \\
\hline \multirow[t]{2}{*}{ Married } & No & 62.5 & 19.9 & 0.848 & 60.0 & 26.7 & 0.218 & 53.9 & 25.8 & 0.421 & 52.3 & 17.4 & 0.379 \\
\hline & Yes & 62.9 & 20.3 & & 56.1 & 27.5 & & 51.4 & 27.4 & & 50.5 & 17.9 & \\
\hline \multirow[t]{2}{*}{ Obese } & No & 63.0 & 19.7 & 0.729 & 56.2 & 27.7 & 0.493 & 53.4 & 27.5 & 0.150 & 51.0 & 17.6 & 0.633 \\
\hline & Yes & 62.2 & 20.1 & & 58.3 & 27.2 & & 49.0 & 25.7 & & 50.0 & 17.9 & \\
\hline \multirow[t]{2}{*}{ Family history of cancer } & No & 64.4 & 19.9 & 0.011 & 58.7 & 28.0 & 0.028 & 54.3 & 28.0 & $0.002 *$ & 51.7 & 17.5 & 0.149 \\
\hline & Yes & 58.9 & 20.5 & & 52.6 & 25.1 & & 46.2 & 23.5 & & 49.0 & 18.4 & \\
\hline \multirow[t]{2}{*}{ 1st year after cancer diagnosis } & No & 63.4 & 20.9 & 0.542 & 58.2 & 28.0 & 0.358 & 51.9 & 27.5 & 0.954 & 51.8 & 17.4 & 0.331 \\
\hline & Yes & 62.2 & 19.6 & & 55.8 & 26.7 & & 51.8 & 26.5 & & 50.1 & 18.0 & \\
\hline \multirow[t]{5}{*}{ Cancer types } & Breast & 61.4 & 20.0 & 0.161 & 58.4 & 28.2 & 0.278 & 49.0 & 26.6 & 0.073 & 50.7 & 19.2 & 0.564 \\
\hline & Colorectal & 65.7 & 20.3 & & 54.6 & 24.0 & & 52.7 & 26.2 & & 50.0 & 14.8 & \\
\hline & Leukemia & 60.9 & 21.8 & & 56.6 & 27.4 & & 56.8 & 25.0 & & 49.1 & 20.6 & \\
\hline & Lymphoma & 67.1 & 21.6 & & 64.2 & 28.7 & & 60.8 & 29.3 & & 54.9 & 16.1 & \\
\hline & Others & 60.5 & 18.5 & & 54.5 & 28.8 & & 49.6 & 27.5 & & 51.2 & 18.2 & \\
\hline \multirow[t]{2}{*}{ Stage III/IV } & $\mathrm{I} / \mathrm{II}$ & 64.0 & 18.7 & 0.011 & 61.8 & 23.9 & $0.001 *$ & 55.4 & 25.5 & $0.001 *$ & 53.3 & 16.0 & $0.001 *$ \\
\hline & III/IV & 58.4 & 21.7 & & 50.7 & 29.4 & & 43.8 & 26.7 & & 46.5 & 18.2 & \\
\hline \multirow[t]{2}{*}{ Multiple tumors } & No & 64.5 & 19.7 & 0.003 & 59.4 & 26.3 & 0.004 & 55.6 & 26.5 & $0.001 *$ & 52.7 & 17.1 & $0.001 *$ \\
\hline & Yes & 58.3 & 20.7 & & 51.2 & 28.8 & & 42.6 & 25.9 & & 46.5 & 18.4 & \\
\hline \multirow[t]{2}{*}{ Cancer surgery } & No & 63.4 & 18.5 & 0.589 & 55.7 & 28.2 & 0.348 & 52.4 & 26.7 & 0.753 & 49.7 & 17.7 & 0.190 \\
\hline & Yes & 62.3 & 21.4 & & 58.1 & 26.6 & & 51.6 & 27.4 & & 52.0 & 17.8 & \\
\hline \multirow[t]{2}{*}{ Chemotherapy } & No & 63.9 & 21.1 & 0.527 & 59.2 & 26.9 & 0.365 & 58.2 & 28.8 & 0.008 & 51.6 & 18.6 & 0.678 \\
\hline & Yes & 62.5 & 19.9 & & 56.3 & 27.5 & & 50.1 & 26.2 & & 50.7 & 17.5 & \\
\hline \multirow[t]{2}{*}{ Radiation therapy } & No & 65.3 & 19.2 & 0.005 & 57.6 & 27.1 & 0.645 & 55.1 & 26.3 & 0.006 & 52.4 & 17.4 & 0.054 \\
\hline & Yes & 59.9 & 21.0 & & 56.3 & 27.8 & & 48.0 & 27.3 & & 49.1 & 18.1 & \\
\hline Immunotherapy & No & 64.5 & 19.3 & 0.073 & 57.4 & 26.4 & 0.771 & 56.9 & 25.8 & $0.001 *$ & 51.4 & 17.3 & 0.615 \\
\hline & Yes & 61.1 & 20.9 & & 56.6 & 28.4 & & 47.9 & 27.2 & & 50.6 & 18.3 & \\
\hline Antibodies & No & 63.4 & 20.4 & 0.333 & 57.5 & 27.5 & 0.332 & 53.0 & 26.1 & 0.431 & 51.1 & 17.5 & 0.993 \\
\hline & Yes & 61.3 & 19.0 & & 54.5 & 27.5 & & 50.4 & 29.6 & & 51.0 & 19.2 & \\
\hline Metastasis & No & 64.9 & 20.2 & $0.001^{*}$ & 59.9 & 26.5 & $0.001 *$ & 56.3 & 26.2 & $0.001 *$ & 53.6 & 17.0 & $0.001 *$ \\
\hline & Yes & 58.1 & 19.4 & & 50.3 & 28.2 & & 42.1 & 26.3 & & 44.8 & 17.9 & \\
\hline Fever & No & 66.4 & 18.5 & $0.001 *$ & 59.7 & 26.4 & 0.010 & 57.1 & 26.2 & $0.001 *$ & 54.1 & 17.8 & $0.001 *$ \\
\hline & Yes & 57.4 & 21.4 & & 52.8 & 28.4 & & 44.1 & 26.4 & & 46.1 & 16.6 & \\
\hline Family support & No & 59.5 & 24.8 & 0.292 & 57.4 & 28.2 & 0.919 & 54.5 & 30.3 & 0.547 & 48.8 & 17.0 & 0.440 \\
\hline & Yes & 63.1 & 19.7 & & 57.0 & 27.3 & & 51.7 & 26.7 & & 51.1 & 17.8 & \\
\hline Chronic disease other than & No & 63.3 & 19.8 & 0.508 & 57.5 & 27.0 & 0.609 & 54.3 & 27.0 & 0.018 & 52.9 & 17.6 & 0.003 \\
\hline cancer & Yes & 62.0 & 20.8 & & 56.1 & 28.0 & & 48.1 & 26.8 & & 47.7 & 17.6 & \\
\hline Regular exercise & No & 60.8 & 20.7 & 0.003 & 53.7 & 27.4 & $0.001 *$ & 48.2 & 26.7 & $0.001 *$ & 48.4 & 17.9 & $0.001 *$ \\
\hline & Yes & 66.9 & 18.4 & & 63.8 & 26.0 & & 59.7 & 26.1 & & 56.2 & 16.3 & \\
\hline
\end{tabular}

*The variable is significant using Bonferroni correction cut-off at $\alpha / n=0.05 / 24=0.0021$, where $n$ is the number of tests, $P=\mathrm{P}$-value. 


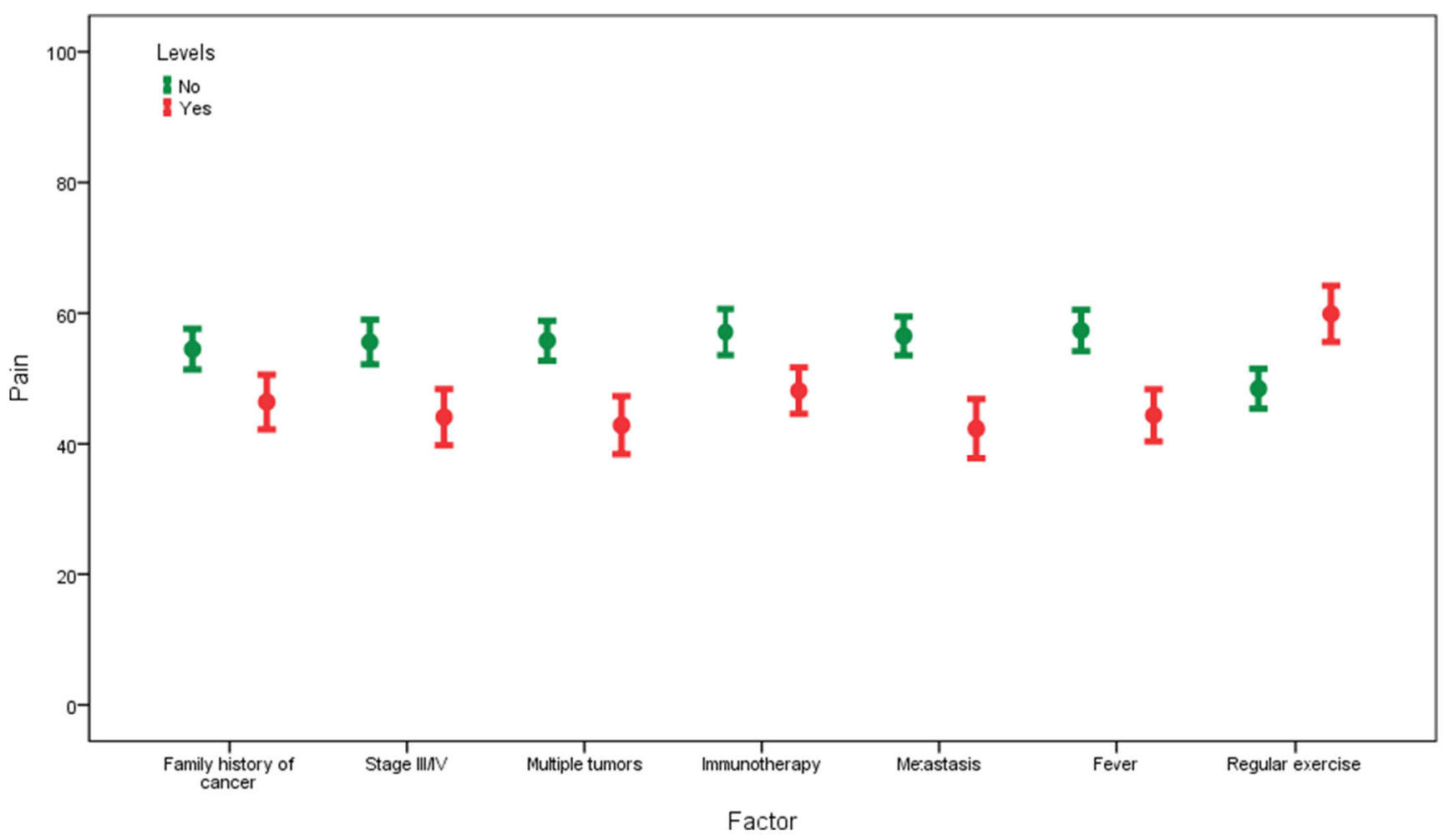

Fig. 1 Error bar chart: impact of cancer complications on bodily pain ratings. Notes: The higher the score, the less pain

\section{Results}

\section{Patients' Characteristics}

Of the 438 cancer patients studied, $64 \%$ were female and $28.4 \%$ had a family history of cancer. The average age of the sample was $52.9( \pm \mathrm{SD}=17.3)$ with a range of $14-97$ years. The median number of months after-cancer diagnoses was 12 (interquartile range 5-24 months). The majority of subjects (76.8\%) received chemotherapy, $41.3 \%$ had cancer stage III or IV, $30.5 \%$ had metastasis, and $24.8 \%$ were treated with antibiotics. Other patient characteristics are reported in Table 1.

\section{Bivariate Analyses}

The mean scores by sociodemographics, clinical symptoms, and cancer treatments of each of the eight QoL domains measured by the SF-36 are presented in Tables 1 and 2 and Fig. 1. The mean physical function was $48.30( \pm \mathrm{SD}=29.4)$. According to subgroup analyses, the elderly, those lacking formal education, the unemployed, those diagnosed with stage III/IV, those with metastasis, and those with chronic disease other than cancer have significantly worse physical functions than the other cancer patients. However, regular exercise was predictive of increasing physical function. Higher mean scores of physical functions were found in patients with breast cancer, followed by patients with leukemia, lymphoma, colorectal, and other cancer types.

The mean scale score for role limitations due to physical health was $25.9( \pm \mathrm{SD}=37.2)$. A greater impact on role limitations due to physical health was found in cancer patients with fever. The mean scale score for role limitations due to emotional problems was $31.6( \pm \mathrm{SD}=41.4)$. Cancer patients with stage III or IV, multiple tumors, and fever reported significantly poorer role limitations due to emotional problems when compared to their counterparts. The mean scale score for vitality was $43.9( \pm \mathrm{SD}=22.0)$, and significantly lower scores on vitality were observed in patients with old age, stage III or IV, multiple tumors, metastasis, and fever when compared to their counterparts. However, patients who regularly exercised reported higher scores on vitality than those who did not exercise.

The mean scale score for emotional wellbeing was 62.8 $( \pm$ SD $=20.2)$. Lower mean scores on emotional wellbeing was found in cancer patients with metastasis and fever when compared to their counterparts. The mean scale score for social functioning was $57.0( \pm \mathrm{SD}=27.4)$. Cancer patients with stage III or IV and metastasis reported significantly lower scores on social functioning when compared to their counterparts, while patients who practiced regular exercise reported higher scores on social functioning than those who did not. The mean scale score for pain was $52.0( \pm \mathrm{SD}=27.0)$. Bodily pain was significantly increased in patients with a family 
history of cancer, stage III or IV, multiple tumors, receiving immunotherapy, metastasis, and fever, while patients who regularly exercised reported less bodily pain than those who did not exercise. The mean scale score for general health was 50.9 $( \pm \mathrm{SD}=17.8)$. Patients with stage III or IV, multiple tumors, metastasis, and fever reported lower scores on general health when compared to their counterparts.

\section{Regression Analyses}

Multivariate analyses (Table 3) showed that elderly and stage III or IV were found to be significant negative predictors of physical health (decrease in physical health scores of 13.79 and 7.82, respectively), while regular exercise was found to be a significant positive predictor of physical health (increase in physical health score of 8.82). A family history of cancer had a negative impact on role limitations due to physical health (decrease in role limitations due to physical health score of 10.3). Patients with chronic disease other than cancer had a positive impact on role limitations due to emotional problems (increase in role limitations due to emotional problem score of 19.66). Poor vitality was predicted by the elderly and those receiving radiation therapy (decrease in vitality scores of 8.11 and 5.92, respectively), while the presence of other chronic diseases and regular exercise were positive predictors of vitality (increase in vitality scores of 5.11 and 5.54, respectively).

Family history of cancer, newly diagnosed cancer patients (first-year-after-cancer diagnosis), radiation therapy, and fever were negatively correlated with poor emotional wellbeing (decrease in emotional wellbeing scores of 7.54, 5.20, 8.05, and 5.54 , respectively), while family support was positively correlated with better emotional wellbeing (increase in emotional wellbeing score of 9.70). Newly diagnosed cancer patients and stage III or IV were negatively correlated with poor social functioning (decrease in social functioning scores of 7.34 and 9.32 , respectively), while regular exercise was positively correlated with better social functioning (increase in social functioning score of 6.66). Cancer stage III or IV and fever had negative impacts on pain (decrease in pain score of 8.08 and 8.01 , respectively). Newly diagnosed cancer patients, leukemia patients, those with metastasis, and those with fever had negative impacts on general health (decrease in pain score of $6.12,10.2,8.34$, and 4.93 , respectively), while those with family support and regular exercise regimens had positive impacts on general health (increase in general health scores of 7.43 and 4.97 , respectively).

\section{Discussion}

This survey addresses health outcomes in a sample of Saudi Arabians with different types of cancer. There is a lack of research addressing health-related quality of life in patients with different cancers in Saudi Arabia. This study is of interest to QoL researchers and providers caring for cancer patients. It has identified several predictors that appear to be correlated with $\mathrm{QoL}$ in cancer patients. One of our findings was that the elderly reported poorer vitality and physical function. These findings are consistent with previous studies in demonstrating older cancer patients may have a negative impact on QoL [5, 6]. It is also evident that patients with first-year-after-cancer diagnosis reported a poorer health-related quality of life. Specifically, patients with first-year-after-cancer diagnosis tended to have poor emotional wellbeing, social function, and general health (decrease in SF-36 scores of 5.20, 7.34, and 6.12, respectively). An Iranian study has also shown that first-year-after-cancer diagnosis is a predictor for poor physical, emotional, and social functioning [24]. Cancer disclosure and patient's quality of life and its impact on cancer treatment and management must be assessed as their relation has yet to be fully studied in Saudi Arabia.

Our study investigated the association between cancer treatments and QoL. Vitality and emotional wellbeing are reported significantly worse among those who received radiation therapy. Several other studies have also shown that poor QoL is linked with cancer treatments [2-4]. An interventional study is warranted to assess the impact of radiation therapy on QoL.

The study also compares the QoL of survivors with different types of cancer. The QoL depends on the location of the cancer. Leukemia was found to be associated with poor quality of life. This has been frequently addressed in various studies [25-27]. QoL assessment in patients with leukemia can provide insights into the effects of leukemia treatment and its management.

This study also investigated the association between regular exercise and QoL of patients with cancers. Other studies have shown similar findings [28-30]. In our study, exercise tended to improve physical function, role limitations due to emotional problems, vitality, social function, and general health (increase in SF-36 scores of 8.82, 9.75, 5.54, 6.66, and 4.97 , respectively). The effectiveness of physical exercise must be assessed in Saudi cancer patients as an intervention to improve QoL and control cancer outcomes. Several limitations were noted. The cross-sectional design may not allow causality assessment. There is a potential for sampling selection bias, in that cancer patients who are attending outpatient clinics may more often be likely to participate, given the perceived severity of their cancer. However, this research has clearly identified several factors that appear to affect QoL in cancer patients.

\section{Conclusions}

Regular exercise in cancer patients was a significant positive predictor of better vitality, social function, and general health. 


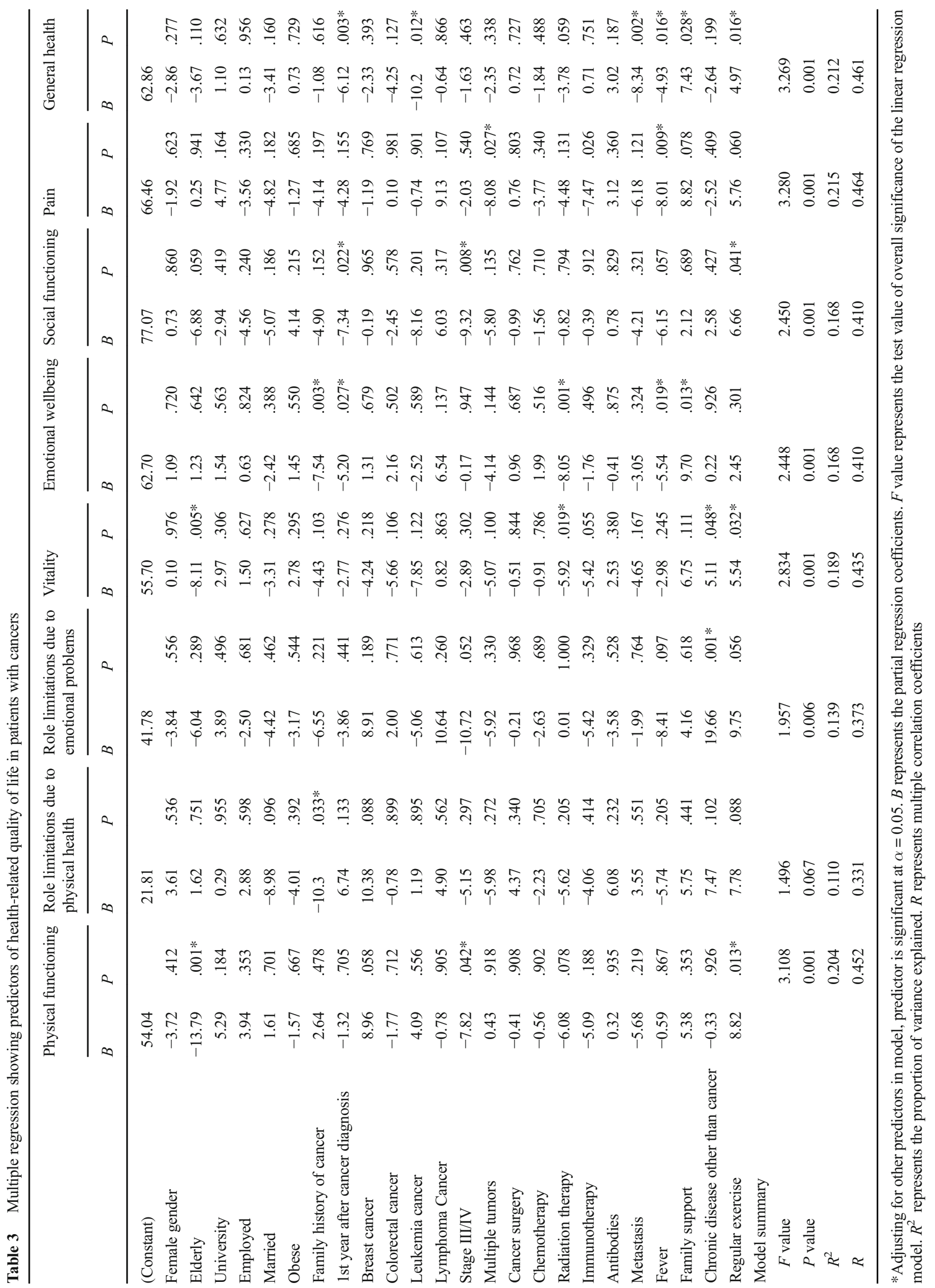


Newly diagnosed cancer patients (first-year-after-cancer diagnosis) tended to experience significantly poor QoL in several domains. The effectiveness of exercise must be assessed in Saudi cancer patients as an intervention to improve QoL.

Acknowledgments The authors would like to express their gratitude to all participants in the study. Thanks to King Abdullah International Medical Research Center for approving this study and for giving us the opportunity to conduct research.

Authors' Contributions AEA was instrumental in development, guidance, progression, data analysis, and writing the manuscript. YZA conducted the statistical analysis. MAA, AGA, ASA, and HSA helped with subject recruitment and data collection and entry. AJ helped with reviewing the manuscript.

\section{Compliance with Ethical Standards}

Funding This study was supported by King Abdullah International Medical Research Center.

Conflict of Interest The authors declare that they have no conflict of interest.

Research Involving Human Participants and/or Animals This article does not contain any studies with human participants or animals performed by any of the authors.

Informed Consent Informed consent was obtained from all individual participants included in the study.

Open Access This article is distributed under the terms of the Creative Commons Attribution 4.0 International License (http:// creativecommons.org/licenses/by/4.0/), which permits unrestricted use, distribution, and reproduction in any medium, provided you give appropriate credit to the original author(s) and the source, provide a link to the Creative Commons license, and indicate if changes were made.

\section{References}

1. Osann K, Hsieh S, Nelson EL, Monk BJ, Chase D, Cella D et al (2014) Factors associated with poor quality of life among cervical cancer survivors: implications for clinical care and clinical trials. Gynecol Oncol 135(2):266-272

2. Pirri C, Bayliss E, Trotter J, Olver IN, Katris P, Drummond P et al (2013) Nausea still the poor relation in antiemetic therapy? The impact on cancer patients' quality of life and psychological adjustment of nausea, vomiting and appetite loss, individually and concurrently as part of a symptom cluster. Support Care Cancer 21(3): 735-748

3. Mock V, Pickett M, Ropka ME, Lin EM, Stewart KJ, Rhodes VA et al (2001) Fatigue and quality of life outcomes of exercise during cancer treatment. Cancer Pract 9(3):119-127

4. Berglund G, Bolund C, Fornander T, Rutqvist LE, Sjödén PO (1991) Late effects of adjuvant chemotherapy and postoperative radiotherapy on quality of life among breast cancer patients. European Journal of Cancer and Clinical Oncology 27(9):10751081
5. Blair CK, Robien K, Inoue-Choi M, Rahn W, Lazovich D (2016) Physical inactivity and risk of poor quality of life among elderly cancer survivors compared to women without cancer: the Iowa Women's Health Study. J Cancer Surviv 10(1):103-112

6. Lindskog M, Tavelin B, Lundström S (2015) Old age as risk indicator for poor end-of-life care quality - a population-based study of cancer deaths from the Swedish Register of Palliative Care. Eur J Cancer 51(10):1331-1339

7. Reyes ME, Ye Y, Zhou Y, Liang A, Kopetz S, Rodriquez MA et al (2016) Predictors of health-related quality of life and association with survival may identify colorectal cancer patients at high risk of poor prognosis. Qual Life Res 4:1-2

8. Ashing-Giwa KT, Lim JW (2009) Examining the impact of socioeconomic status and socioecologic stress on physical and mental health quality of life among breast cancer survivors. In: Oncology nursing forum, Vol. 36, No. 1

9. Ell K, Xie B, Wells A, Nedjat-Haiem F, Lee PJ, Vourlekis B (2008) Economic stress among low-income women with cancer. Cancer 112(3):616-625

10. Zebrack BJ, Yi J, Petersen L, Ganz PA (2008) The impact of cancer and quality of life for long-term survivors. Psycho-Oncology 17(9): 891-900

11. Ramsey SD, Berry K, Moinpour C, Giedzinska A, Andersen MR (2002) Quality of life in long term survivors of colorectal cancer. Am J Gastroenterol 97(5):1228-1234

12. Bilal S, Doss JG, Cella D, Rogers SN (2015) Quality of life associated factors in head and neck cancer patients in a developing country using the FACT-H\&N. J Cranio-Maxillofac Surg 43(2): 274-280

13. Strøm HH, Bremnes RM, Sundstrøm SH, Helbekkmo N, Fløtten Ø, Aasebø U (2013) Concurrent palliative chemoradiation leads to survival and quality of life benefits in poor prognosis stage III non-small-cell lung cancer: a randomised trial by the Norwegian Lung Cancer Study Group. Br J Cancer 109(6): 1467-1475

14. Fosså SD, Curran D, Aaronson NK, Keuppens F, Kliment J, Robinson MR et al (2000) Quality of life of patients with newly diagnosed poor prognosis M1 prostate cancer undergoing orchiectomy without or with mitomycin C. Eur Urol 37(5):541-551

15. Rathod S, Livergant J, Klein J, Witterick I, Ringash J (2015) A systematic review of quality of life in head and neck cancer treated with surgery with or without adjuvant treatment. Oral Oncol 51(10): 888-900

16. Almutairi KM, Alhelih E, Al-Ajlan AS, Vinluan JM (2016) A cross-sectional assessment of quality of life of colorectal cancer patients in Saudi Arabia. Clin Transl Oncol 18(2):144-152

17. Almutairi KM, Mansour EA, Vinluan JM (2016) A cross-sectional assessment of quality of life of breast cancer patients in Saudi Arabia. Public health 136:117-25

18. Ahmed AE, Alharbi AG, Alsadhan MA, Almuzaini AS, Almuzaini HS, Ali YZ et al (2017) The predictors of poor quality of life in a sample of Saudi women with breast cancer. Breast Cancer-Targets and Therapy 9:1-8

19. Aaronson NK, Ahmedzai S, Bergman B, Bullinger M, Cull A, Duez NJ et al (1993) The European Organization for Research and Treatment of Cancer QLQ-C30: a quality-of-life instrument for use in international clinical trials in oncology. J Natl Cancer Inst 85(5):365-376

20. Ware JE, Sherbourne CD (1992) The MOS 36-item short-form health survey (SF-36). Med Care 30(6):473-483. doi:10.1097/ 00005650-199206000-00002

21. Ahmed AE, Alaskar AS, Al-Suliman AM, Jazieh AR, McClish DK, Al Salamah M et al (2015) Health-related quality of life in patients with sickle cell disease in Saudi Arabia. Health Qual Life Outcomes 13(1):1 
22. Ahmed AE, Alaskar AS, McClish DK, Ali YZ, Aldughither MH, Al-Suliman AM et al (2016) Saudi SCD patients' symptoms and quality of life relative to the number of ED visits. BMC Emergency Medicine 16(1):30

23. Coons SJ, Alabdulmohsin SA, Draugalis JR, Hays RD (1998) Reliability of an Arabic version of the RAND 36-Item Health Survey and its equivalence to the US-English version. Med Care 36:428-432. doi:10.1097/00005650-199803000-00018

24. Montazeri A, Tavoli A, Mohagheghi MA, Roshan R, Tavoli Z (2009) Disclosure of cancer diagnosis and quality of life in cancer patients: should it be the same everywhere? BMC Cancer 9(1):1

25. Holzner B, Kemmler G, Kopp M, Nguyen-Van-Tam D, SpernerUnterweger B, Greil R (2004) Quality of life of patients with chronic lymphocytic leukemia: results of a longitudinal investigation over 1 yr. Eur J Haematol 72(6):381-389
26. Shanafelt TD, Bowen D, Venkat C, Slager SL, Zent CS, Kay NE et al (2007) Quality of life in chronic lymphocytic leukemia: an international survey of 1482 patients. Br J Haematol 139(2):255-264

27. Oliva EN, Nobile F, Alimena G, Ronco F, Specchia G, Impera S et al (2011) Quality of life in elderly patients with acute myeloid leukemia: patients may be more accurate than physicians. Haematologica 96(5):696-702

28. Gerritsen JK, Vincent AJ (2016) Exercise improves quality of life in patients with cancer: a systemic review and meta-analysis of randomized controlled trials. Brit J Sport Med 50(13):796-803

29. Courneya KS, Friedenreich CM (1999) Physical exercise and quality of life following cancer diagnosis: a literature review. Ann Behav Med 21(2):171-179

30. Speed-Andrews AE, Courneya KS (2009) Effects of exercise on quality of life and prognosis in cancer survivors. Current sports medicine reports 8(4):176-181 